\title{
Risk Factors of Peritoneal Recurrence and Outcome of Resected Peritoneal Recurrence After Liver Resection in Hepatocellular Carcinoma: Review of 1222 Cases of Hepatectomy in a Tertiary Institution
}

\author{
Alfred Wei Chieh Kow, FRCSEd ${ }^{1}$, Choon Hyuck David Kwon, MD, $\mathrm{PhD}^{2}$, Sanghyun Song, $\mathrm{MD}^{2}$, Milljae Shin, $\mathrm{MD}^{2}$, \\ Jong Man Kim, MD, $\mathbf{P h D}^{2}$, and Jae-Won Joh, MD, $\mathbf{P h D}^{2}$ \\ ${ }^{1}$ Department of HPB Surgery and Liver Transplantation, University Surgical Cluster, National University Health System, \\ Singapore, Singapore; ${ }^{2}$ Department of Surgery, Samsung Medical Center, Sungkyunkwan University School of Medicine, \\ Seoul, South Korea
}

\begin{abstract}
Background. Reports on the risk factors of peritoneal recurrence (PR) after liver resection for hepatocellular carcinoma are lacking. We examined the risk factors of PR after hepatectomy and the outcome of resected PR at our institution.

Methods. We retrospectively reviewed the data from 1,222 patients who underwent hepatectomies for hepatocellular carcinoma in Samsung Medical Center from January 2006 to August 2010. We identified patients with PR and studied the risk factors and outcomes of resected PR.

Results. The rate of PR was $3.0 \% \quad(n=36)$. The mean $\pm \mathrm{SD}$ age of patients was $54.0 \pm 10.2$ years. Among those with PR, 23 patients $(63.9 \%)$ had unresectable disease and 13 patients $(36.1 \%)$ had resectable disease. Multivariate analysis found that tumor size $>50 \mathrm{~mm}$, presence of microvascular invasion, bile duct invasion, and positive margins were significant risk factors of PR after liver resection. The median overall survival (OS) for resectable PR was 33.0 (28.0-61.6) months compared to 14.0 (6.8-21.2) months for unresectable PR $(P=0.009)$. Cox regression analysis demonstrated that resected $\mathrm{PR}$ [hazard ratio (HR) $0.042, P=0.001$ ] and interval between hepatectomy and PR ( $>$ 6months) (HR 0.195, $P=0.016$ )
\end{abstract}

(C) The Author(s) 2012. This article is published with open access at Springerlink.com

First Received: 31 August 2011;

Published Online: 9 March 2012

C. H. D. Kwon, MD, PhD

e-mail: chdkwon@skku.edu were positive prognostic factors for OS, while alfa-fetoprotein $>200 \mathrm{ng} / \mathrm{dl}$ at detection of PR (HR 11.321, $P=0.015)$ and serosal involvement of primary hepatocellular carcinoma (HR 25.616, $P=0.007$ ) were negative prognostic factors for OS.

Conclusions. We found that tumor size $>50 \mathrm{~mm}$, presence of microvascular invasion, bile duct invasion, and positive resection margins were significant risk factors of PR after liver resection. Selected patients with resected PR had significantly better OS.

Hepatocellular carcinoma (HCC) is a highly prevalent malignancy, affecting approximately over half a million people worldwide. ${ }^{1}$ In Korea, HCC is the third leading malignancy after stomach and lung cancers. According to 2005 statistics, the age-adjusted incidence of primary HCC is 44.9 per 100,000 men. ${ }^{2,3}$ Chronic hepatitis B is endemic in Korea, representing the most important risk factor, constituting approximately $70 \%$ of all cases of HCC., ${ }^{4,5}$ Although liver transplantation for $\mathrm{HCC}$ has altered the natural history of this disease, liver resection remains one of the main treatment modalities that provides good outcome..$^{6-10}$

Peritoneal implantation in $\mathrm{HCC}$ is uncommon, with reported incidences ranging 2-16\%. ${ }^{11-14}$ Generally, peritoneal recurrence (PR) in HCC was considered to be an incurable terminal disease. Patients are rarely suitable for surgical resection of PR in HCC. Reports on the long-term outcome PR resection are lacking in the literature. A few anecdotal case reports have documented satisfactory outcome after surgical resection of PR in HCC. ${ }^{15-22}$ One of the largest series was a report from a Taiwanese center, reporting a median survival of 16 months in patients who underwent 
resection of peritoneal implantation. ${ }^{23}$ However, studies on the risk factors of PR and resected peritoneal lesions remain rare in the literature. There is a lack of recommendations in the management of PR in HCC after resection.

Selected patients with PR after liver resection underwent resection of the peritoneal lesions at our institution. Our primary aim was to investigate the risk factors influencing PR in HCC after liver resection. A secondary aim was to determine the predictive factors for resected PR after liver resection and its long-term outcome. From this information, we drew up guidelines for resection of PR in HCC after hepatectomy.

\section{PATIENTS AND METHODS}

We performed retrospective data collection of all patients who underwent liver resection for HCC at Samsung Medical Center, South Korea, from January 2006 to September 2010. After excluding patients who were lost to follow-up, 1,222 cases were suitable for analysis. During the process of data collection, we identified patients with PR documented by imaging studies and those who underwent resection of PR.

Demographic details (including the causative factor of HCC) and prehepatectomy tumor marker levels [alfa-fetoprotein (AFP) and protein induced by vitamin $\mathrm{K}$ absence or antagonist-II (PIVKA-II)] and other treatment modalities (e.g., radiofrequency ablation, transarterial chemoembolization) were collected from patients' electronic medical records. Surveillance of patients with HCC after liver resection was performed at 3 month intervals for the first 2 years and then every 4-6 months thereafter. During the visit, tumor markers such as AFP and PIVKA-II were assayed. Elevated tumor markers prompted the suspicion of tumor recurrence, and further investigations were performed to ascertain the diagnosis. Options of the radiologic imaging included computed tomographic scan of the abdomen and pelvis (with computed tomography of the thorax), magnetic resonance imaging, and/or positron emission tomography scan.

The aim of the investigations was twofold. First, the investigations would help determine the locations of recurrences, number of lesions, and whether they were resectable. Second, the presence of extra-abdominal metastases that would preclude further curative resection would be ascertained. In the absence of other systemic metastasis or inoperable intrahepatic recurrences of $\mathrm{HCC}$, if the peritoneal lesions were resectable and without compromising essential anatomic structures such as major vasculature, surgical resection would be offered to the patient.

After ascertaining that PRs were suitable for resection, the next step was to ensure that the selected patients were fit to undergo the operation. Careful preoperative assessment was carried out. At the operation, a midline incision was made to facilitate exploratory laparotomy. Careful adhesiolysis was performed to avoid enterotomy when adhesion was encountered. Locations and number of lesions were confirmed with the preoperative scans. Resection of the peritoneal lesions was carefully performed to ensure adequate surgical margin. En-bloc resection of the lesion, along with its surrounding structures, such as the small bowel or the cuff of diaphragm, was occasionally required. In situations where the malignant nature of the lesion was uncertain, excision for frozen section histology was performed intraoperatively. Careful hemostasis and selective placement of abdominal drains at surgical sites were performed.

Postoperative histologic assessment and reporting included maximum tumor diameter, Edmonson grade of HCC, microvascular invasion (MVI), portal vein/hepatic vein invasion, bile duct invasion, serosal involvement, intrahepatic metastasis, multicentric occurrence of HCC, and resection margin. tumor, node, metastasis system staging was performed in accordance with the American Joint Committee on Cancer (seventh edition) staging system. ${ }^{24}$ R0 resection status was defined as the presence of microscopic tumor $>1 \mathrm{~mm}$ from the resection margin. There was no patient with $\mathrm{R} 2$ resection in this cohort.

Detailed information of patients who were identified to have PR was recorded. The interval from hepatectomy to PR was documented. For those who developed unresectable PR (commonly as a result of concurrent systemic metastasis to other sites such as lung and bone, or unresectable intrahepatic recurrence), radiologic information on

TABLE 1 Pattern of distribution of PR in the study cohort $(n=36)$

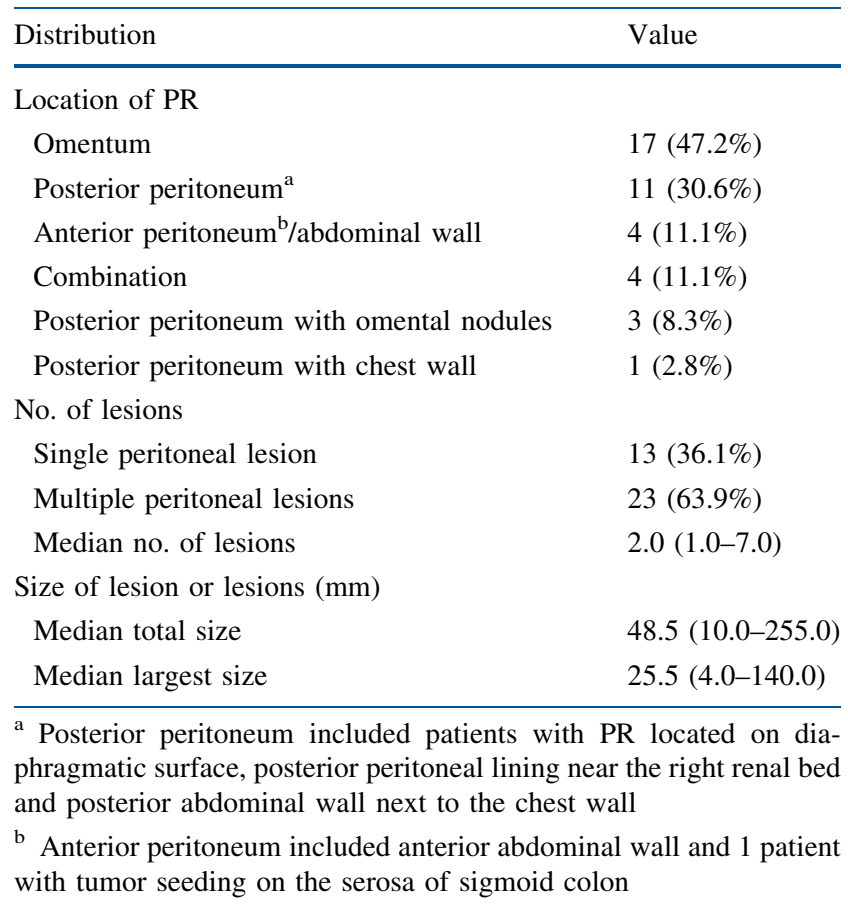


TABLE 2 Univariate analysis of risk factors of PR $(n=1222)$

\begin{tabular}{|c|c|c|c|c|}
\hline Parameter & $\begin{array}{l}\text { All } \\
(n=1222)\end{array}$ & $\begin{array}{l}\text { NPR group } \\
(n=1186)\end{array}$ & $\begin{array}{l}\text { PR group } \\
(n=36)\end{array}$ & $P$ \\
\hline Age (year), mean $\pm \mathrm{SD}$ & $54.0 \pm 10.2$ & $54.0 \pm 10.2$ & $51.0 \pm 10.3$ & 0.545 \\
\hline \multicolumn{5}{|l|}{ Gender } \\
\hline Male & $977(80.0 \%)$ & $946(79.7 \%)$ & $31(86.1 \%)$ & \multirow[t]{2}{*}{0.349} \\
\hline Female & $245(20.0 \%)$ & $240(20.2 \%)$ & $5(13.9 \%)$ & \\
\hline \multicolumn{5}{|l|}{ Cause of HCC } \\
\hline Chronic hepatitis B & $940(78.2 \%)$ & $913(78.4 \%)$ & $26(72.2 \%)$ & \multirow[t]{3}{*}{0.883} \\
\hline Chronic hepatitis C & $62(5.2 \%)$ & $60(5.1 \%)$ & $2(5.6 \%)$ & \\
\hline Other (alcoholic liver disease, etc.) & $200(21.5 \%)$ & $192(16.5 \%)$ & $8(22.2 \%)$ & \\
\hline History of ruptured HCC & $14(1.2 \%)$ & $12(1.0 \%)$ & $2(5.6 \%)$ & $0.012 *$ \\
\hline Treatment before hepatectomy & $198(16.2 \%)$ & $189(15.9 \%)$ & $9(25.0 \%)$ & 0.426 \\
\hline TACE & $165(83.3 \%)$ & $158(83.6 \%)$ & $7(77.8 \%)$ & 0.879 \\
\hline RFA & $18(9.1 \%)$ & $17(9.0 \%)$ & $1(11.1 \%)$ & \\
\hline Both RFA and TACE & $15(7.6 \%)$ & $14(7.4 \%)$ & $1(11.1 \%)$ & \\
\hline \multicolumn{5}{|l|}{ Method of surgical access } \\
\hline Open & $1143(93.8 \%)$ & $1110(93.8 \%)$ & $33(91.7 \%)$ & \multirow[t]{3}{*}{0.138} \\
\hline Laparoscopic & $70(5.7 \%)$ & $68(5.7 \%)$ & $2(5.6 \%)$ & \\
\hline Laparoscopic converted to open & $6(0.5 \%)$ & $5(0.4 \%)$ & $1(2.8 \%)$ & \\
\hline \multicolumn{5}{|l|}{ Types of hepatectomy } \\
\hline Nonanatomic resection & $573(46.9 \%)$ & $562(47.4 \%)$ & $11(30.6 \%)$ & \multirow[t]{2}{*}{$0.046^{*}$} \\
\hline Anatomic resection & $649(53.1 \%)$ & $624(52.6 \%)$ & $25(69.4 \%)$ & \\
\hline Right hemihepatectomy & $251(20.5 \%)$ & $238(20.1 \%)$ & $13(36.1 \%)$ & \multirow[t]{11}{*}{0.051} \\
\hline Left hemihepatectomy & $3(0.2 \%)$ & $2(0.2 \%)$ & $1(2.8 \%)$ & \\
\hline Posterior sectionectomy & $125(10.2 \%)$ & $121(10.2 \%)$ & $4(11.1 \%)$ & \\
\hline Anterior sectionectomy & $21(1.7 \%)$ & $20(1.7 \%)$ & $1(2.8 \%)$ & \\
\hline Extended right hepatectomy & $30(2.5 \%)$ & $29(2.4 \%)$ & $1(2.8 \%)$ & \\
\hline Extended left hepatectomy & $20(1.6 \%)$ & $20(1.7 \%)$ & $0(0.0 \%)$ & \\
\hline Left lateral sectionectomy & $137(11.2 \%)$ & $134(11.3 \%)$ & $3(8.3 \%)$ & \\
\hline Anatomic monosegmentectomy & $13(1.1 \%)$ & $13(1.1 \%)$ & $0(0.0 \%)$ & \\
\hline Central hepatectomy & $49(4.0 \%)$ & $47(4.0 \%)$ & $2(5.6 \%)$ & \\
\hline Bisegmentectomy & $67(5.5 \%)$ & $65(5.5 \%)$ & $2(5.6 \%)$ & \\
\hline Subsegmentectomy & $506(41.4 \%)$ & $497(41.9 \%)$ & $9(25.0 \%)$ & \\
\hline \multicolumn{5}{|l|}{ Preoperative blood parameters } \\
\hline Prehepatectomy AFP level, mean \pm SD & $5759.3 \pm 64351.8$ & $5391.8 \pm 64691.7$ & $17785.8 \pm 51292.2$ & 0.186 \\
\hline $\mathrm{AFP} \leq 400 \mathrm{ng} / \mathrm{ml}$ & $922(75.9 \%)$ & $898(76.2 \%)$ & $24(66.7 \% 0$ & \multirow[t]{2}{*}{0.189} \\
\hline $\mathrm{AFP}>400 \mathrm{ng} / \mathrm{ml}$ & $293(24.1 \%)$ & $281(23.8 \%)$ & $12(33.3 \%)$ & \\
\hline Prehepatectomy PIVKA-II level, mean \pm SD & $209.3 \pm 306.2$ & $209.8 \pm 307.2$ & $192.5 \pm 267.8$ & 0.888 \\
\hline Size of HCC at hepatectomy, mm, median (range) & $35.0(2.0-210.0)$ & $35.0(2.0-210.0)$ & $45.5(13.0-170.0)$ & $0.001 *$ \\
\hline \multicolumn{5}{|l|}{ Stratification of size of $\mathrm{HCC}$} \\
\hline Tumor $\leq 50 \mathrm{~mm}$ & $892(73.0 \%)$ & $871(73.4 \%)$ & $21(58.3 \%)$ & \multirow[t]{2}{*}{$0.002 *$} \\
\hline Tumor $>50 \mathrm{~mm}$ & $330(27.0 \%)$ & $315(26.6 \%)$ & $15(41.7 \%)$ & \\
\hline \multicolumn{5}{|l|}{ Edmonson grade } \\
\hline I and II & $1095(91.6 \%)$ & $1064(91.5 \%)$ & $31(93.9 \%)$ & \multirow[t]{2}{*}{0.617} \\
\hline III and IV & $101(8.4 \%)$ & $99(8.5 \%)$ & $2(6.1 \%)$ & \\
\hline \multicolumn{5}{|l|}{$\mathrm{T}$ stage of $\mathrm{HCC}$} \\
\hline $\mathrm{T} 1$ and $\mathrm{T} 2$ & $963(80.8 \%)$ & $943(81.3 \%)$ & $20(62.5 \%)$ & \multirow[t]{2}{*}{$0.008 *$} \\
\hline T3 and T4 & $229(19.2 \%)$ & $217(19.7 \%)$ & $12(37.5 \%)$ & \\
\hline
\end{tabular}


TABLE 2 continued

\begin{tabular}{|c|c|c|c|c|}
\hline Parameter & $\begin{array}{l}\text { All } \\
(n=1222)\end{array}$ & $\begin{array}{l}\text { NPR group } \\
(n=1186)\end{array}$ & $\begin{array}{l}\text { PR group } \\
(n=36)\end{array}$ & $P$ \\
\hline Combined $\mathrm{HCC}$ and IHCC & $38(3.1 \%)$ & $35(3.0 \%)$ & $3(8.3 \%)$ & 0.067 \\
\hline \multicolumn{5}{|l|}{ Invasion/involvement } \\
\hline Tumor capsule involvement & $1024(85.4 \%)$ & $995(85.4 \%)$ & $29(85.3 \%)$ & 0.985 \\
\hline Microvascular invasion & $645(52.8 \%)$ & $618(52.1 \%)$ & $27(75.0 \%)$ & $0.007 *$ \\
\hline Bile duct invasion & $35(2.9 \%)$ & $31(2.7 \%)$ & $4(11.8 \%)$ & $0.002 *$ \\
\hline Portal vein invasion & $90(7.5 \%)$ & $84(7.2 \%)$ & $6(17.6 \%)$ & $0.022 *$ \\
\hline Serosal involvement & $15(1.3 \%)$ & $13(1.1 \%)$ & $2(5.9 \%)$ & $0.014 *$ \\
\hline Intrahepatic metastasis & $165(13.7 \%)$ & $158(13.5 \%)$ & $7(20.6 \%)$ & 0.238 \\
\hline Multicentric occurrence & $59(4.9 \%)$ & $58(5.0 \%)$ & $1(2.9 \%)$ & 0.590 \\
\hline Totally necrotic nodule & $21(1.7 \%)$ & $18(1.5 \%)$ & $3(8.3 \%)$ & $0.002 *$ \\
\hline Resection margin, mm, median (range) & $10.0(0.0-80.0)$ & $10.0(0.0-80.0)$ & $8.0(0.0-45.0)$ & 0.360 \\
\hline \multicolumn{5}{|l|}{ Resection } \\
\hline R0 & $1183(97.7 \%)$ & $1152(98.0 \%)$ & $31(88.6 \%)$ & $<0.001 *$ \\
\hline R1 & $28(2.3 \%)$ & $24(2.0 \%)$ & $4(11.4 \%)$ & \\
\hline
\end{tabular}

TACE transarterial chemoembolization, RFA radiofrequency ablation, IHCC intrahepatic cholangiocacinoma

* Statistically significant at $P<0.05$

TABLE 3 Multivariate analysis for risk factors of peritoneal recurrence of HCC after hepatectomy by logistic regression

\begin{tabular}{llll}
\hline Independent risk factor for PR & OR & $95 \%$ CI & $P$ \\
\hline Ruptured HCC & 3.800 & $0.668-21.929$ & 0.132 \\
Anatomic vs. nonanatomic resection & 2.375 & $0.212-1.107$ & 0.123 \\
Tumor > 50 mm & 1.368 & $1.023-3.112$ & $0.032^{*}$ \\
T stage of tumor (T1 and T2 vs. T3 & 0.901 & $0.356-2.282$ & 0.815 \\
$\quad$ and T4) & & & \\
Positive resection margin & 9.540 & $1.746-18.733$ & $0.042^{*}$ \\
Microvascular invasion & 3.896 & $1.164-8.165$ & $0.023^{*}$ \\
Bile duct invasion & 3.720 & $1.179-12.279$ & $0.025^{*}$ \\
Portal vein invasion & 0.508 & $0.583-5.000$ & 0.476 \\
Serosal involvement & 3.184 & $0.813-28.042$ & 0.074 \\
Totally necrotic nodule & 0.596 & $0.316-24.602$ & 0.440
\end{tabular}

OR odds ratio, $C I$ confidence interval

* Significant at $P<0.05$

the number, size, and site of peritoneal lesions was measured from the scan. For patients who underwent resection of PR, the operative and histologic data (including number and size of lesions, as well as the location of lesions) were clearly documented. Preoperative imaging findings on the number, size, and site of peritoneal lesions were also measured from the scan to allow comparison with unresectable PRs. Information on subsequent recurrence of peritoneal lesions and other sites of recurrence in this group of patients was also recorded. Overall survival (OS) was analyzed as the time from the date of hepatectomy until the date of death (i.e., death from all causes, including dead of disease and dead of other causes), whichever occurred first. Patients lost to follow-up or for whom the event of interest had yet been observed were censored at the date last known to be alive.

A total of 1,222 patients who underwent liver resection for HCC during the study duration were accrued. We studied the different parameters between two groups of patients with and without PR after liver resection. We classified the patients into those without PR (NPR) and those with PR. Further analysis of resected and unresectable PR was performed.

Data were analyzed by SPSS software, version 17.0 (SPSS, Chicago, IL). Statistical significance was set at a $P$ value of $<0.05$. The $\chi^{2}$ test was used in cross-tabulation of nominal data. Student's $t$ test was performed for parametric continuous variables, and the Mann-Whitney $U$ test was used for nonparametric continuous variables. Logistic and linear regression analyses were used to investigate the predictors of PR. Kaplan-Meier analysis was used to depict the OS and difference in survival between study groups.

\section{RESULTS}

\section{Distribution of Patients and Pattern of Distribution of $P R$}

The mean $\pm \mathrm{SD}$ age of this cohort was $54.0 \pm$ 10.2 years. There were 1,186 patients $(97.0 \%)$ in the NPR group and 36 patients $(3.0 \%)$ in the PR group. Within the PR group, 23 patients $(63.9 \%)$ had unresectable PR, and another 13 patients $(36.1 \%)$ underwent resection of PR. 
The median time from hepatectomy to PR was 6.5 (1.0-102.0) months. The most common site of PR was at the omentum $(n=17,47.2 \%)$. One-third of patients had a single lesion $(n=13,36.1 \%)$. The median number of lesions was $2.0(1.0-7.0)$ (Table 1).

\section{Analysis of Clinicopathologic Factors Influencing PR}

The demographic data in the NPR and PR groups were not statistically significant. Nine patients $(25 \%)$ in the PR group received other treatments before hepatectomy, compared to 189 patients $(15.9 \%)$ in the NPR group $(P=$ $0.426)$. There were significantly more patients in the $P R$ group who had ruptured HCC $(n=2,5.6 \%)$ before liver resection compared to the NPR group $(n=12,1.0 \%)$ $(P=0.012)$. Slightly more than half $(n=624,52.6 \%)$ of the liver resections in the NPR group were anatomic resections, compared to $69.4 \%(n=25)$ in the PR group $(P=0.046)$ (Table 2).

The median tumor size of HCC in the PR group was $45.5(13.0-170.0) \mathrm{mm}$, significantly larger by $10.5 \mathrm{~mm}$ compared to the median tumor size of HCC in the NPR group (median $35.0 \mathrm{~mm}$, range $2.0-210.0 \mathrm{~mm}, \quad P=$ 0.001 ). The proportion of tumors $>50 \mathrm{~mm}$ in size in the PR group was $41.7 \%(n=15)$ compared to $26.6 \%(n=315)$ in the NPR group $(P=0.002)$. There was a significantly larger proportion of T3 and T4 tumors in the PR group $(n=12,37.5 \%)$ compared to the NPR group $(n=217$, $18.7 \%)(P=0.008)$. The rates of MVI $(P=0.007)$, bile duct invasion $(P=0.002)$, portal vein/hepatic vein invasion $(P=0.022)$, serosal involvement $(P=0.014)$, and totally necrotic nodule $(P=0.002)$ in the PR group were significantly higher compared to the NPR group. Furthermore, there was a significantly higher proportion of HCC specimens with positive resection margin in the PR group $(n=4,11.4 \%)$ compared to the NPR group $(n=24$, $2.0 \%)(P<0.001)$.

\section{Multivariate Analysis for Risk Factors of PR}

The above factors found to be statistically significant on univariate analysis were examined by multivariate analysis. By means of logistic regression, we found that tumor size $>50 \mathrm{~mm}$ [odds ratio (OR) $1.368, P=0.032$ ], presence of MVI (OR 3.896, $P=0.023$ ), bile duct invasion (OR 3.720, $P=0.025$ ), and positive resection margins (OR 9.540, $P=0.042)$ were significant predictors of $\mathrm{PR}$ after liver resection for HCC in this cohort (Table 3).

\section{Information at Time of Detection of PR}

Twenty-three patients (63.9\%) had unresectable PR, while another 13 patients $(36.1 \%)$ underwent resection of
TABLE 4 Information at the time of detection of PR

\begin{tabular}{llll}
\hline $\begin{array}{l}\text { Clinicopathologic } \\
\text { factors }\end{array}$ & $\begin{array}{l}\text { Unresectable PR } \\
(n=23)\end{array}$ & $\begin{array}{l}\text { Resectable PR } \\
(n=13)\end{array}$ & $P$ \\
\hline $\begin{array}{l}\text { Interval between } \\
\text { hepatectomy and }\end{array}$ & $6.0(1.0-43.0)$ & 11.0 & $0.009 *$ \\
$\quad \begin{array}{l}\text { PR, mo, median } \\
\text { (range) }\end{array}$ & & \\
Interval between hepatectomy and peritoneal & \\
$\begin{array}{l}\text { Recurrence } \\
\leq 6 \text { month }\end{array}$ & $13(56.5 \%)$ & $5(38.4 \%)$ & 0.080 \\
$>6$ month & $10(43.4 \%)$ & $8(61.5 \%)$ &
\end{tabular}

Tumor markers at PR

AFP level, $\quad 16519.7 \pm 45832.1575 .4 \pm 1475.2 \quad 0.032 *$ mean $\pm \mathrm{SD}$

AFT level

$\begin{array}{clll}\leq 200 \mathrm{ng} / \mathrm{dl} & 13(56.5) & 10(76.9) & 0.221 \\ >200 \mathrm{ng} / \mathrm{dl} & 10(43.5) & 3(23.1) & \\ \text { PIVKA-II level } & & & \\ \text { Mean } \pm \mathrm{SD} & 407.0 \pm 498.1 & 180.5 \pm 348.8 & 0.034^{*} \\ \leq 200 \mathrm{mAU} / \mathrm{ml} & 11(55.0) & 10(83.3) & 0.102 \\ >200 \mathrm{mAU} / \mathrm{ml} & 9(45.0) & 2(16.7) & \\ \text { No. of peritoneal } & 2.0(1.0-7.0) & 1.0(1.0-4.0) & 0.044^{*}\end{array}$

No. of peritoneal $2.0(1.0-7.0) \quad 1.0(1.0-4.0) \quad 0.044 *$

lesions, median (range)

$\begin{array}{llll}\text { Single lesion } & 6(26.1 \%) & 7(53.8 \%) & 0.096 \\ \text { Multiple lesions } & 17(73.9 \%) & 6(46.2 \%) & \end{array}$

Size of largest peritoneal lesion

$\begin{array}{llll}\begin{array}{l}\text { Median (range), } \\ \mathrm{mm}\end{array} & 24.0(4.0-60.0) & \begin{array}{c}35.0 \\ (10.0-140.0)\end{array} & 0.070 \\ \leq 30 \mathrm{~mm} & 16(69.6) & 7(30.4) & 0.069 \\ >30 \mathrm{~mm} & 5(38.5) & 8(61.5) & \end{array}$

Total size of peritoneal lesion

\begin{tabular}{llll}
$\begin{array}{l}\text { Median (range), } \\
\mathrm{mm}\end{array}$ & $47.0(20.0-255)$ & $\begin{array}{c}60.0 \\
(10.0-140.0)\end{array}$ & 0.499 \\
$\leq 50 \mathrm{~mm}$ & $14(60.9)$ & $9(39.1)$ & 0.196 \\
$>50 \mathrm{~mm}$ & $5(38.5)$ & $8(61.5)$ & \\
$\begin{array}{l}\text { Location of PR } \\
\text { Omentum }\end{array}$ & $17(73.9 \%)$ & $0(0.0 \%)$ & $<0.001^{*}$ \\
$\begin{array}{l}\text { Posterior } \\
\text { peritoneum }\end{array}$ & $4(17.4 \%)$ & $7(53.8 \%)$ & \\
$\begin{array}{l}\text { Anterior } \\
\text { peritoneal/ } \\
\text { abdominal wall }\end{array}$ & $2(8.7 \%)$ & $2(15.4 \%)$ & \\
$\begin{array}{l}\text { Combination } \\
\begin{array}{l}\text { Posterior } \\
\text { peritoneum with } \\
\text { omental nodules }\end{array}\end{array}$ & $0(0.0 \%)$ & $4(30.8 \%)$ & \\
$\begin{array}{l}\text { Posterior } \\
\text { peritoneum with } \\
\text { chest wall }\end{array}$ & - & $3(23.1 \%)$ & \\
$\begin{array}{l}\text { Omental seeding } \\
\text { Other }\end{array}$ & $17(73.9 \%)$ & $3(23.1 \%)$ & $<0.003 *$ \\
\hline
\end{tabular}

* Statistically significant at $P<0.05$ 
PR. The median interval between hepatectomy and PR in the resected group was 11.0 (range 1.0-102.0) months, 5.0 months longer than the unresectable group (median 6.0 months, range $1.0-43.0$ months, $P=0.009)$. There were almost $20 \%$ more patients with a disease-free interval of $>6$ months in the resected PR group $(61.5 \%$ in the resected group vs. $43.4 \%$ in unresectable group, $P=0.080$ ) (Table 4).

At the time of detection of PR, the median number of lesion in the unresectable group was 2.0 (range 1.0-7.0), compared to 1.0 (range 1.0-4.0) in the resected group $(P=0.044)$. Although we were unable to demonstrate statistical significance, the proportion of patients with solitary lesions in the resectable group $(n=7,53.8 \%)$ was doubled that in the unresectable group $(n=6,26.1 \%)$, with close to three-quarters of patients in the unresectable group having multiple peritoneal lesions at recurrence ( $n=17,73.9 \%)(P=0.096)$. In terms of location, the most common site of peritoneal metastasis in patients with unresectable PR was at the omentum (73.9\%); posterior peritoneal lining (including diaphragm) was the most common site in resected PR $(53.8 \%)(P<0.001)$.

\section{Long-Term Outcome (Survival Analysis) of PR}

The OS for patients in the NPR group was significantly better compared to that in the PR group $(P<0.001)$. The 1-, 3-, and 5-year OS for the NPR group was 87.0, 76.0, and $72.0 \%$, respectively, compared to that in the PR group, which was 48.0, 23.0, and 14.0\%, respectively (Fig. 1a).

However, the median OS for resected PR was significantly longer (33.0 months) compared to patients with unresectable PR (14.0 months) $(P=0.009)$ (Fig. 1b). The 1-, 3-, and 5-year OS of patients with resected PR was 71.0, 48.0 , and $48.0 \%$, compared to $30.0,6.0$, and $6.0 \%$, respectively, for patients with unresectable PR
$(P<0.001)$. Figure 2 a shows the OS for various groups of recurrences in comparison with resected and unresectable PR. Resected PR was found to have comparable OS compared with patients with only intrahepatic HCC recurrence $(P=0.340)$ (Fig. 2 b) but was significantly better than patients with other types of nonintrahepatic HCC recurrence $(P=0.008)$ (Fig. 2c).

\section{Prognostic Factors of $O S$ for Patients with PR}

By univariate analysis, we found that resected PR $(P=$ $0.005)$, prehepatectomy AFP $>400 \mathrm{ng} / \mathrm{dl} \quad(P=0.008)$, HCC size $>50 \mathrm{~mm}(P=0.023)$, higher Edmonson grade $(P=0.033)$, serosal involvement $(P=0.002)$, interval between hepatectomy and $\mathrm{PR}>6$ months $(P=0.001)$, and AFP at detection of PR $>200 \mathrm{ng} / \mathrm{dl}(P=0.008)$ were significant factors. The use of sorafenib was not found to have any survival benefit $(P=0.092)$ (Table 5).

By Cox regression analysis, we found that resected PR [hazard ratio (HR) $0.042, P=0.001$ ] and an interval between hepatectomy and PR of $>6$ months (HR 0.181, $P=0.001)$ were positive predictors of OS in patients with PR. On the other hand, serosal involvement at primary HCC (HR 25.616, $P=0.007$ ) and AFP at detection of PR (HR 11.321, $P=0.010$ ) had a significant negative influence on the survival of patients with PR.

\section{Information on Resected PR}

Eight patients $(61.5 \%)$ with resected PR were still alive at the study's completion. Patients with fewer lesions and long intervals between hepatectomy and PR had a much better outcomes compared to those with numerous peritoneal lesions. Five patients (38.4\%) experienced recurrent peritoneal lesions, but only one underwent further resection. Another patient had recurrence at the chest wall and
FIG. 1 a OS of HCC patients comparing the NPR group and the PR group after hepatectomies at a tertiary institution. b OS of patients with resectable and unresectable PR after hepatectomies for HCC

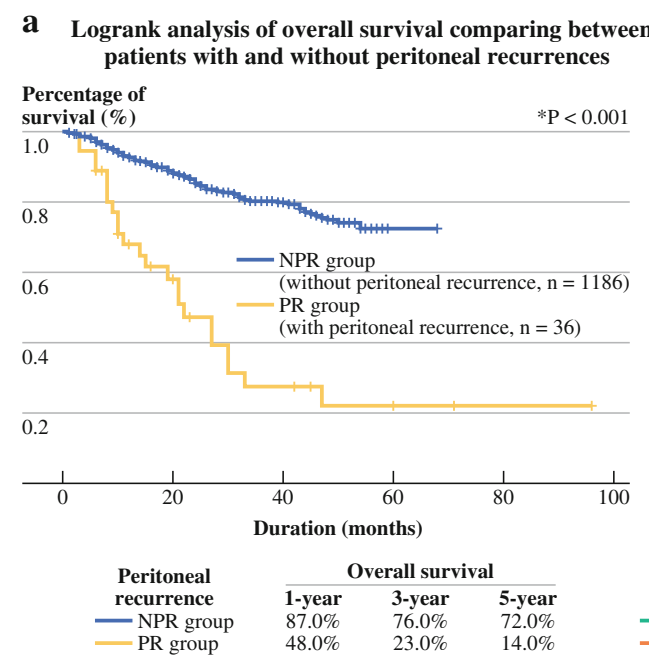

b

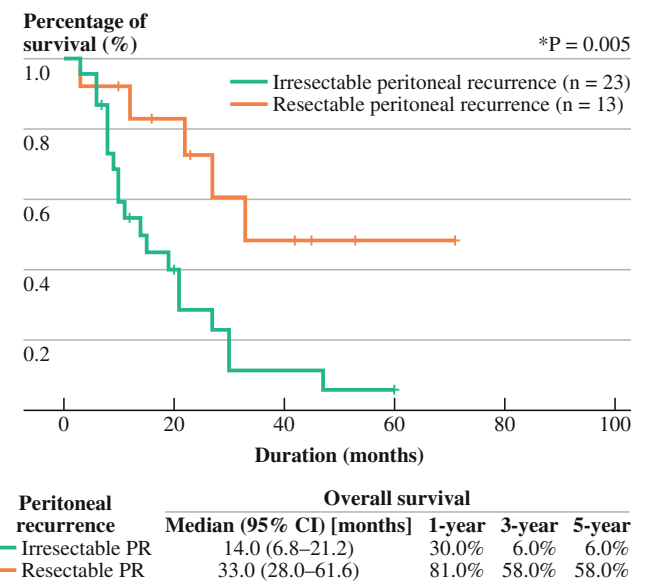


a

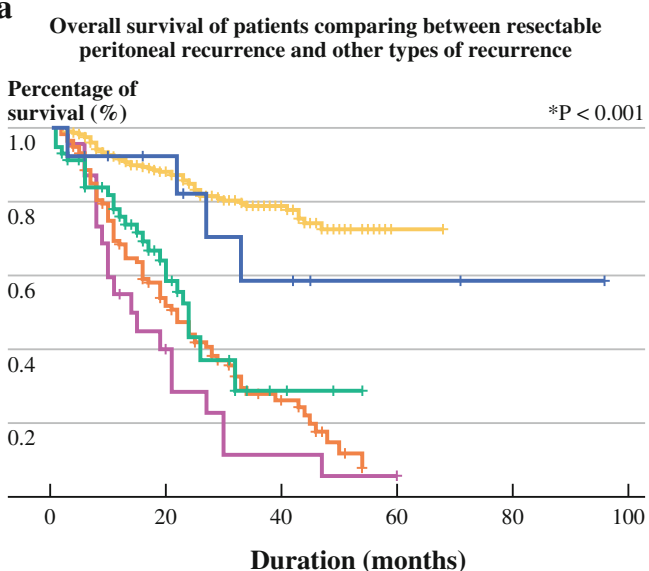

\begin{tabular}{cccc} 
& \multicolumn{3}{c}{ Overall survival } \\
\cline { 2 - 4 } Types of recurrence(s) in HCC & 1-year & 3-year & $\mathbf{5}$-year \\
Resectable PR $(\mathrm{n}=13)$ & $81 \%$ & $58 \%$ & $58 \%$ \\
\hline $\begin{array}{c}\text { Intraheptic recurrence } \\
\text { only }(\mathrm{n}=279)\end{array}$ & $86 \%$ & $72 \%$ & $72 \%$ \\
\hline $\begin{array}{c}\text { Intraheptic \& other non-PR } \\
\text { recurrence }(\mathrm{n}=115)\end{array}$ & $48 \%$ & $19 \%$ & $6 \%$ (4 years) \\
Non-intraheptic non-PR & & & \\
$\quad \begin{array}{c}\text { recurrence }(\mathrm{n}=57) \\
\text { Irresectable PR }(\mathrm{n}=23)\end{array}$ & $54 \%$ & $28 \%$ & $28 \%$ (4 years) \\
& $30 \%$ & $6 \%$ & $6 \%$
\end{tabular}

b Overall survival comparing between resectable peritoneal recurrence and intraheptic reccurence (only) of $\mathrm{HCC}$

\section{Percentage o}

survival (\%)

1.0

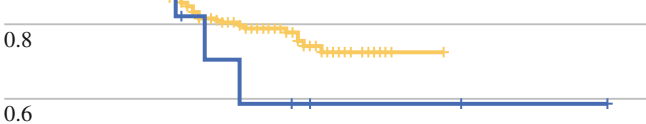

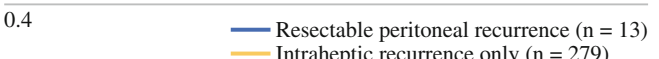

0.2

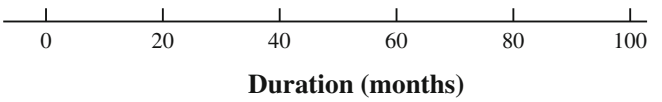
Overall survival of patients with resectable peritoneal
recurrence and other types of recurrence of HCC

Percentage of (excluding intraheptic recurrence)

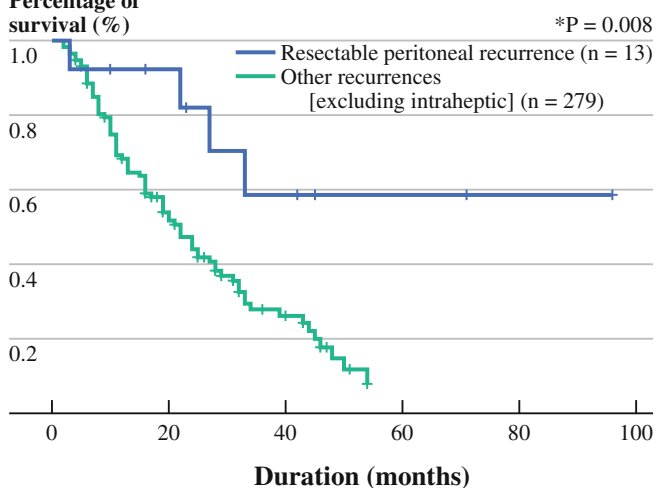

FIG. 2 a Comparison of OS of resectable PR with other types of recurrence of HCC after liver resection. b Comparison of OS between resectable $\mathrm{PR}$ with intrahepatic recurrence only for $\mathrm{HCC}$ after curative resection. c Comparison of OS of patients with resectable PR with other types of recurrence (excluding intrahepatic recurrence) underwent resection. Three patients survived more than 5 years. All three of them also had a long interval between hepatectomy and detection of PR (48, 52, and 102 months, respectively) (Table 6). One of them has since died.

\section{DISCUSSION}

After resection, tumor recurrence rate is exceedingly high in HCC, reaching about $70 \%$ at 5 years. ${ }^{7,25-27}$ Most of the recurrences occur within the liver. Common sites of systemic metastasis of HCC after resection are lungs, bones, and brain. Other systemic sites such as adrenal glands, spleen, pancreas, and ovaries are usually not detected until autopsy. ${ }^{28-30}$ PR in $\mathrm{HCC}$ is uncommon. The reported incidence ranged $2-16 \% .{ }^{11-14,31}$ In our series, the PR rate was $3.0 \%$. The rate of unresectable PR was $1.9 \%$, while another $1.1 \%$ underwent resection of PR after liver resection.

Because PRs after hepatectomy for HCC are rare, many previous reports related to PRs were included in studies focusing on extrahepatic recurrences. In comparison, our study solely examined the risk factors of PR in the cohort of patients. Cha et al. from Memorial Sloan-Kettering Cancer Center reported that tumor size of $>5 \mathrm{~cm}$ and presence of vascular invasion were significant predictors of extrahepatic recurrences in HCC after resection. These two factors were similarly found to be significant predictors for PR in our cohort. Furthermore, a positive resection margins was not found to be a significant factor as a result of its low frequency in their study. ${ }^{32}$ In contrast, we found that positive resection margin was a significant predictor of PR, whereas presence or portal vein/hepatic vein invasion was not. Furthermore, the presence of bile duct invasion was found to increase the risk of PR in our study. In terms of the pattern of distribution of PR, we noted that the omentum was the most common site (47.2\%), followed by the posterior peritoneal lining (inclusive of parietal peritoneal surface of diaphragm). This was consistent with the pattern observed in the study by Yeh et al., in which omental nodules constituted $50 \%$ of all cases. ${ }^{23}$ However, it is important to emphasize that our series included both resectable and unresectable PR, whereas Yeh et al. studied only resected PR patients.

Ruptured tumor has commonly been postulated to increase the risk of PR in HCC. Most of the reports on peritoneal metastasis after ruptured HCC were case reports. Many of the reports note that peritoneal metastases occurred 8 months after tumor rupture, although some occurred as early as $3-4$ months after ruptured HCC. ${ }^{33,34}$ In our study, there were only two patients in the PR group with a history of ruptured HCC. One of them developed four isolated peritoneal lesions 1 month after hepatectomy 
TABLE 5 Univariate and multivariate analyses of overall survival in patients with PR

\begin{tabular}{|c|c|c|c|c|c|c|}
\hline \multirow[t]{2}{*}{ Factor } & \multicolumn{3}{|c|}{ Univariate analysis } & \multicolumn{3}{|c|}{ Multivariate analysis } \\
\hline & HR & $95 \% \mathrm{CI}$ & $P$ & HR & $95 \% \mathrm{CI}$ & $P$ \\
\hline PR resectable & 0.207 & $0.069-0.621$ & $0.005 *$ & 0.042 & $0.007-0.262$ & $0.001 *$ \\
\hline Prehepatectomy AFP > 400 ng/dl & 3.232 & $1.353-7.721$ & $0.008 *$ & 0.458 & $0.067-3.120$ & 0.425 \\
\hline Prehepatic PIVKA-II > $200 \mathrm{mAU} / \mathrm{ml}$ & 2.124 & $0.805-5.604$ & 0.128 & & & \\
\hline HCC size $>50 \mathrm{~mm}$ & 2.645 & $1.142-6.126$ & $0.023 *$ & 0.819 & $0.150-4.482$ & 0.818 \\
\hline Edmonson grade III and IV & 5.759 & $1.151-28.808$ & $0.033 *$ & 0.156 & $0.023-1.041$ & 0.055 \\
\hline Stratified T stage of HCC (III and IV) & 1.882 & $0.795-4.456$ & 0.150 & & & \\
\hline Microvascular invasion & 2.157 & $0.721-6.452$ & 0.169 & & & \\
\hline Portal vein invasion & 2.344 & $0.845-6.500$ & 0.102 & & & \\
\hline Bile duct invasion & 1.603 & $0.533-4.826$ & 0.401 & & & \\
\hline Serosal involvement & 22.271 & $3.054-162.407$ & $0.002 *$ & 25.616 & $2.436-269.313$ & $0.007 *$ \\
\hline Positive resection margin & 3.870 & $0.790-18.953$ & 0.095 & & & \\
\hline Interval between hepatectomy and PR $>6$ mo & 0.181 & $0.064-0.514$ & $0.001 *$ & 0.195 & $0.041-0.922$ & $0.039 *$ \\
\hline AFP at detection of $\mathrm{PR}>200 \mathrm{ng} / \mathrm{dl}$ & 1.884 & $0.927-3.829$ & $0.008 *$ & 11.321 & $1.766-72.581$ & $0.010^{*}$ \\
\hline PIVKA-II at detection of PR $>200 \mathrm{mAU} / \mathrm{ml}$ & 0.852 & $0.402-1.808$ & 0.677 & & & \\
\hline Single vs. multiple peritoneal lesions & 1.996 & $0.815-4.890$ & 0.131 & & & \\
\hline Omental seeding vs. other locations & 0.450 & $0.184-1.099$ & 0.080 & & & \\
\hline Size of largest peritoneal lesion $>30 \mathrm{~mm}$ & 1.363 & $0.594-3.125$ & 0.465 & & & \\
\hline Total size of peritoneal lesions $>50 \mathrm{~mm}$ & 1.096 & $0.482-2.495$ & 0.827 & & & \\
\hline
\end{tabular}

CI confidence interval

* Statistically significant at $P<0.05$

and underwent resection of those lesions (because no other distant metastasis was noted). Another patient developed seven disseminated peritoneal nodules with multiple intrahepatic lesions at 6 months after liver resection after ruptured $\mathrm{HCC}$ and was treated conservatively. This differs greatly from many reports suggesting that a single metastatic nodule is the most common presentation for PR after ruptured HCC. ${ }^{33,34}$ Shin et al. reported a patient who survived a long time with recurred HCC after three bouts of repeated hepatic resection for intrahepatic recurrences and one bout of right hemicolectomy for an omental recurrence. $^{35}$ In the current study, ruptured $\mathrm{HCC}$ was a significant factor for PR by univariate analysis but did not show significance on multivariate analysis, probably as a result of the low incidence of ruptured HCC in our cohort $(n=14,1.2 \%)$.

Tumor markers levels, such as prehepatectomy PIVKAII, AFP, and PIVKA-II level at detection of PR, were all significantly higher in patients with unresectable PR. This could indicate that the higher tumor load and the disseminated nature of the disease could preclude them from undergoing potentially curative surgical resection of PR. Indeed, most of the patients with unresectable PR had concomitant intrahepatic tumor recurrence and/or other systemic metastases. We also found that patients with smaller HCC $(\leq 50 \mathrm{~mm})$ and lower $\mathrm{T}$ stage of tumor at primary hepatectomy were more likely to undergo resection of PR. In addition, they also had significantly fewer lesions (median 1.0, range 1.0-4.0) compared to those resectable disease (median 2.0, range 1.0-7.0). In this regard, Yeh and Chen reported that tumor capsule invasion and elevated AFP level $>400 \mathrm{ng} / \mathrm{ml}$ were significant predictors of peritoneal implantation after hepatectomy. ${ }^{13}$

Reports on the long-term survival outcome of patients with peritoneal metastasis after hepatectomy are scarce in the literature, leading to a lack of recommendations in the management of PR in HCC. In general, when PR occurs in HCC, surgical resection with curative intent would not be considered. In one rare report of 20 year data by Lin et al., patients with metachronous peritoneal metastasis experienced a median survival of 12.5 months-significantly longer than those who did not undergo PR resection (2.1 months).$^{14}$ In addition, Nakayama et al. reported that resection of peritoneal metastases arising from HCC is justified because patients experienced disease-free survival and OS of 11.8 to 81.6 months after salvage therapy. ${ }^{12}$ In our series, the median OS for resected PR was 33.0 months, which was significantly longer than patients with unresectable PR (median OS 15.0 months). The 5 year survival for resectable PR was $48.0 \%$, compared to $6.0 \%$ in patients with unresectable PR.

Some patients with PR after resection of HCC may experience good long-term survival if the peritoneal metastasis was resected. In the current study, in addition to 
TABLE 6 Information on resected PR

\begin{tabular}{|c|c|c|c|c|c|c|c|c|}
\hline $\begin{array}{l}\text { Patient } \\
\text { no. }\end{array}$ & Details of resected PR & $\begin{array}{l}\text { No. of } \\
\text { lesions }\end{array}$ & $\begin{array}{l}\text { Size of } \\
\text { largest } \\
\text { lesion }(\mathrm{mm})\end{array}$ & $\begin{array}{l}\text { Total size of } \\
\text { lesions } \\
(\mathrm{mm})\end{array}$ & $\begin{array}{l}\text { Interval between } \\
\text { hepatectomy and PR } \\
\text { (month) }\end{array}$ & $\begin{array}{l}\text { Overall } \\
\text { survival } \\
\text { (month) }\end{array}$ & $\begin{array}{l}\text { Survival } \\
\text { status }\end{array}$ & $\begin{array}{l}\text { Further } \\
\text { recurrent } \\
\text { peritoneal } \\
\text { lesions }\end{array}$ \\
\hline 1 & $\begin{array}{l}\text { Peritoneal mass, abdominal } \\
\text { wall nodule and subxiphoid } \\
\text { mass }\end{array}$ & 4 & 40 & 125 & 9 & 10 & Alive & No \\
\hline 2 & Peritoneal mass and omentum & 4 & 50 & 86 & 1 & 3 & Dead & $\begin{array}{l}\text { Yes, resected } \\
\text { chest wall } \\
\text { lesion }\end{array}$ \\
\hline 3 & $\begin{array}{l}\text { Omentum, splenic hilum at } \\
\text { lesser curve }\end{array}$ & 3 & 50 & 130 & 19 & 33 & Dead & $\begin{array}{l}\text { Yes, not } \\
\text { resectable }\end{array}$ \\
\hline 4 & Lesser sac, caudate lobe and & 3 & 35 & 70 & 2 & 6 & Alive & $\begin{array}{l}\text { Yes, resected } \\
\text { peritoneal } \\
\text { lesion }\end{array}$ \\
\hline 5 & $\begin{array}{l}\text { Right upper quadrant mass and } \\
\text { right chest wall }\end{array}$ & 2 & 50 & 100 & 18 & 45 & Alive & $\begin{array}{l}\text { Yes, not } \\
\text { resectable }\end{array}$ \\
\hline 6 & $\begin{array}{l}\text { Omentum and diaphragmatic } \\
\text { nodule }\end{array}$ & 2 & 35 & 58 & 48 & 102 & Alive & No \\
\hline 7 & $\begin{array}{l}\text { Subdiaphragmatic mass with } \\
\text { en bloc resection of } \\
\text { diaphragm }\end{array}$ & 1 & 23 & 23 & 102 & 115 & Dead & No \\
\hline 8 & Abdominal wall mass & 1 & 15 & 15 & 52 & 71 & Alive & No \\
\hline 9 & $\begin{array}{l}\text { Right-sided abdominal wall } \\
\text { mass }\end{array}$ & 1 & 10 & 10 & 19 & 42 & Alive & No \\
\hline 10 & Peritoneal nodule & 1 & 12 & 12 & 6 & 23 & Alive & No \\
\hline 11 & $\begin{array}{l}\text { Abdominal wall at rectus } \\
\text { abdominis }\end{array}$ & 1 & 21 & 21 & 6 & 22 & Dead & No \\
\hline 12 & $\begin{array}{l}\text { Anterior aspect of duodenum } \\
\text { and peritoneum on head of } \\
\text { pancreas }\end{array}$ & 1 & 60 & 60 & 6 & 27 & Dead & $\begin{array}{l}\text { Yes, not } \\
\text { resectable }\end{array}$ \\
\hline 13 & $\begin{array}{l}\text { Metastasis to SB and sigmoid } \\
\text { colon }\end{array}$ & 1 & 140 & 140 & 11 & 16 & Alive & $\begin{array}{l}\text { Yes, not } \\
\quad \text { resectable }\end{array}$ \\
\hline
\end{tabular}

resection of the peritoneal lesions, longer interval between hepatectomy and detection of $\mathrm{PR}>6$ months was a positive prognostic factor for OS. On the other hand, presence of serosal involvement and high AFP levels of $>200 \mathrm{ng} / \mathrm{dl}$ at detection of PR were significant negative predictors of survival in PR. Indeed, a long disease-free interval suggested that there was a subset of patients with better tumor biology, and thus the peritoneal metastasis took a much longer time to become clinically evident. This group of patients would certainly experience better long-term survival after peritoneal metastasectomy. There were a few long-term survivors in our series with disease-free intervals of more than 48 months and an OS of more than 5 years. Two were still alive at the time of last follow-up.

Although resection of $\mathrm{HCC}$ was associated with a high incidence of recurrence, aggressive therapy for the recurrence is a key strategy in prolonging survival. On the basis of our analysis, we strongly recommend that surgical resection of PR be offered as an option as part of a multimodality therapy in $\mathrm{HCC}$ after hepatectomy in selected patients. Suitable candidates include patients with small tumor size ( $\mathrm{HCC} \leq 50 \mathrm{~mm}$ ), low $\mathrm{T}$ stage of tumor, prehepatectomy PIVKA-II level of $<200 \mathrm{mg} / \mathrm{dl}$, low AFP level at detection of PR $(<200 \mathrm{ng} / \mathrm{dl})$, and long interval between hepatectomy and PR ( $>6$ months).

Finally, we acknowledge that the retrospective nature of this analysis is a limitation of the study. The study could potentially underestimate the real incidence of PR, which was the reason why we reviewed such a large series of patients and went through their post-HCC resection scans in such detail. Further prospective studies would result in a better understanding of this condition. However, we recognize that this would be a difficult task because of the low incidence of PR in HCC.

In conclusion, peritoneal metastases of $\mathrm{HCC}$ are rare. Risk factors that we identified as predictors of PR after hepatectomy for HCC included tumor size $>50 \mathrm{~mm}$, presence of MVI, bile duct invasion, and positive resection margins. Selected patients with small tumor size $(\mathrm{HCC} \leq 50 \mathrm{~mm})$, low $\mathrm{T}$ stage of tumor, prehepatectomy 
PIVKA-II level $<200 \mathrm{mg} / \mathrm{dl}$, low AFP level at detection of PR $(<200 \mathrm{ng} / \mathrm{dl})$, and long interval between hepatectomy and resected PR ( $>6$ months) would be suitable candidates for resection of PR.

OPEN ACCESS This article is distributed under the terms of the Creative Commons Attribution License which permits any use, distribution, and reproduction in any medium, provided the original author(s) and the source are credited.

\section{REFERENCES}

1. McGlynn KA, Tsao L, Hsing AW, Devasa SS, Fraumeni JF Jr. International trends and patterns of primary liver cancer. Int $J$ Cancer. 2001;94:290-6.

2. National Cancer Center. Annual reports of the Korea Central Cancer Registry. 2003. http://www.ncc.re.kr.

3. Jung K-W, Won Y-J, Park S, Kong H-J, Sung J, Shin H-R, Park E-C, Lee JS. Cancer statistics in Korea: incidence, mortality and survival in 2005. J Korean Med Sci. 2009;24:995-1003.

4. Huh K, Choi SY, Whang YS, Lee DS. Prevalence of viral hepatitis markers in Korean patients with hepatocellular carcinoma. J Korean Med Sci. 1998;13:306-10.

5. Song IH, Kim KS. Current status of liver diseases in Korea: hepatocellular carcinoma. Korean J Hepatol. 2009;15(Suppl 6): S50-9.

6. Bruix J, Sherman M. Management of hepatocellular carcinoma: an update. AASLD practice guideline. Hepatology (in press).

7. Llovet JM, Fuster J, Bruix J. Intention-to-treat analysis of surgical treatment for early hepatocellular carcinoma: resection versus transplantation. Hepatology. 1999;30:1434-40.

8. Arii S, Yamaoka Y, Futagawa S, et al. Results of surgical and nonsurgical treatment for small-sized hepatocellular carcinomas: a retrospective and nationwide survey in Japan. The Liver Cancer Study Group of Japan. Hepatology. 2000;32:1224-9.

9. Takayama T, Makuuchi M, Hirohashi S, et al. Early hepatocellular carcinoma as an entity with a high rate of surgical cure. Hepatology. 1998;28:1241-6.

10. Fong Y, Sun RL, Jarnagin W, Blumgart LH. An analysis of 412 cases of hepatocellular carcinoma at a Western center. Ann Surg. 1999;229:790-9.

11. Kasai Y, Tamaki A, Kakita H. Surgical treatment of primary hepatocellular carcinoma. Geko Shinryo. 1977;19:46-54.

12. Nakayama H, Takayama $T$, Makuuchi $M$, et al. Resection of peritoneal metastasis from hepatocellular carcinoma. Hepatogastroenterology. 1999;46:1049-52.

13. Yeh CN, Chen MF. Resection of peritoneal implantation of hepatocellular carcinoma after hepatic resection: risk factors and prognostic analysis. World J Surg. 2004;28:382-6.

14. Lin CC, Liang HP, Lee HS, et al. Clinical manifestations and survival of hepatocellular carcinoma patients with peritoneal metastasis. J Gastroenterol Hepatol. 2009;24:815-20.

15. Yoshida H, Onda M, Tajiri T, et al. Successful surgical treatment of peritoneal dissemination of hepatocellular carcinoma. Hepatogastroenterology. 2002;49:1663-5.

16. Kurachi K, Suzuki S. Yokoi Y, et al. A 5-year survivor after resection of peritoneal metastases from pedunculated-type hepatocellular carcinoma. J Gastroenterol. 2002;37:571-4.

17. Terasaki T, Hanazaki K, Shiohara E, Matsunaga Y, Koide N, Amano J. Complete disappearance of recurrent hepatocellular carcinoma with peritoneal dissemination and splenic metastasis: a unique clinical course after surgery. $J$ Gastroenterol Hepatol. 2000; $15: 327-30$

18. Takahashi H, Konishi M, Nakagohri T, et al. Aggressive multimodal treatment for peritoneal dissemination and needle tract implantation of hepatocellular carcinoma: a case report. Jpn J Clin Oncol. 2004;34:551-5.

19. Ryu JK, Lee SB, Kim KH, Yoh KT. Surgical treatment in a patient with multiple implanted intraperitoneal metastases after resection of ruptured hepatocellular carcinoma. Hepatogastroenterology. 2004;51:239-42.

20. Kosaka A, Hayakawa H, Masayuki K, et al. Successful surgical treatment for implanted intraperitoneal metastases of ruptured small HCC: report of a case. Surg Today. 1999;29:453-7.

21. Erigushi N, Aoyagi S, Okuda K, et al. Successful treatment for implanted intraperitoneal metastases of HCC. J Hepatobiliary Pancreat Surg. 2000;7:520-3.

22. Hung MC, Wu HS, Lee YT, Hsu CH, Chou DA, Huang MH. Intraperitoneal metastasis of hepatocellular carcinoma after spontaneous rupture: a case report. World J Gastroenterol. 2008;14:3927-31.

23. Yeh CN, Chen MF, Jeng LB. Resection of peritoneal implantation from hepatocellular carcinoma. Ann Surg Oncol. 2002;9:863-8.

24. Edge SB, Byrd DR, Compton CC, Fritz AG, Greene FL, Trotti A (eds). American Joint Committee on Cancer (AJCC) Cancer Staging Manual. 7th ed. New York: Springer; 2009 p. 237.

25. Okada S, Shimada K, Yamamoto J, et al. Predictive factors for postoperative recurrence of hepatocellular carcinoma. Gastroenterology. 1994;106:1618-24.

26. Poon RT, Fan ST, Lo CM, Liu CL, Wong J. Inrahepatic recurrence after curative resection of hepatocellular carcinoma: long term results of treatment and prognostic factors. Ann Surg. 1999;229:216-22.

27. Adachi E, Maeda T, Matsumata T, et al. Risk factors for intrahepatic recurrence in human small hepatocellular carcinoma. Gastroenterology. 1995;108;768-75.

28. Lee YTM, Geer DA. Primary liver cancer: pattern of metastasis. J Surg Oncol. 1987;36:26-31.

29. Makashima T, Okuda K, Kojiro M, et al. Pathology of hepatocellular carcinoma in Japan:232 consecutive cases autopsied in ten years. Cancer. 1983;51:863-77.

30. Liver Cancer Study Group of Japan. Primary liver cancer in Japan. Cancer. 1987;60:1400-11.

31. Natsuizaka M, Omura T, Akaike T, et al. Clinical features of hepatocellular carcinoma with extrahepatic metastases. J Gastroenterol Hepatol. 2005;20:1781-7.

32. Cha C, Fong Y, Jarnagin WR, Blumgart LH, DeMatteo RP. Predictors and patterns of recurrence after resection of hepatocellular carcinoma. J Am Coll Surg. 2003;197:753-8.

33. Ong GB, Chu EPH, Yu FYK, Lee TC. Spontaneous rupture of hepatocellular carcinoma. Br J Surg. 1965;52:123-9.

34. Dixon JM, Nirmul D, Eremin O. Hemoperitoneum due to traumatic rupture of a hepatoma in a patient with hemochromatosis. $J$ R Coll Surg Edinb. 1982;27:362-3.

35. Shin SH, Kim IH, Lee DS, Yun SS, Kim HJ. [Repeat resection for intrahepatic and omental recurrence of ruptured hepatocellular carcinoma after the initial surgery]. Korean $J$ Hepatobiliary Pancreat Surg. 2006;10:42-7. 